Supplementary information for:

\title{
Differential removal of nanoparticles on the surface of a thin film substrate
}

Haoxian Lu, Fengwen Huang, Hai Guo*

Air Quality Studies, Department of Civil and Environmental Engineering, The Hong Kong Polytechnic University, Hong Kong, China

*Corresponding author. ceguohai@polyu.edu.hk

Summary:

Pages: S1-S3.

Figures: S1-S5.

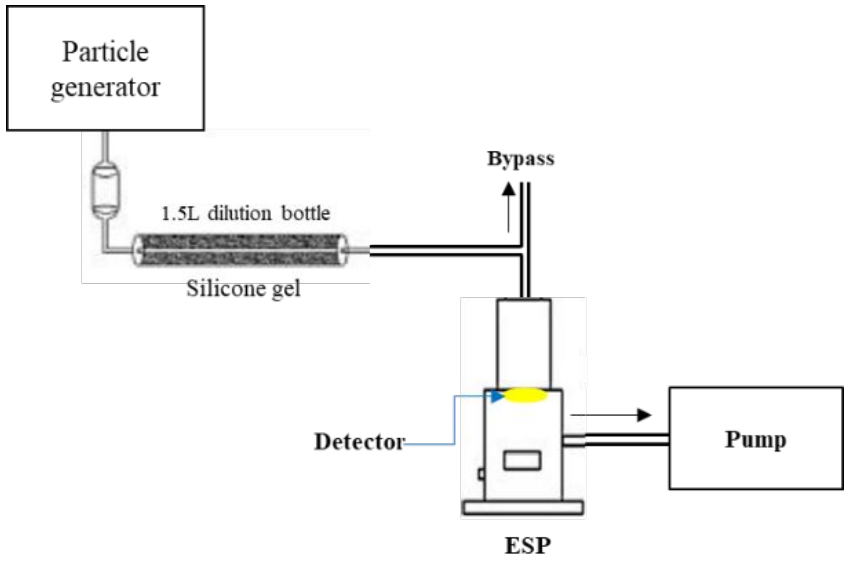

Figure S1 Generation and collection system of standard non-acidic particles. 


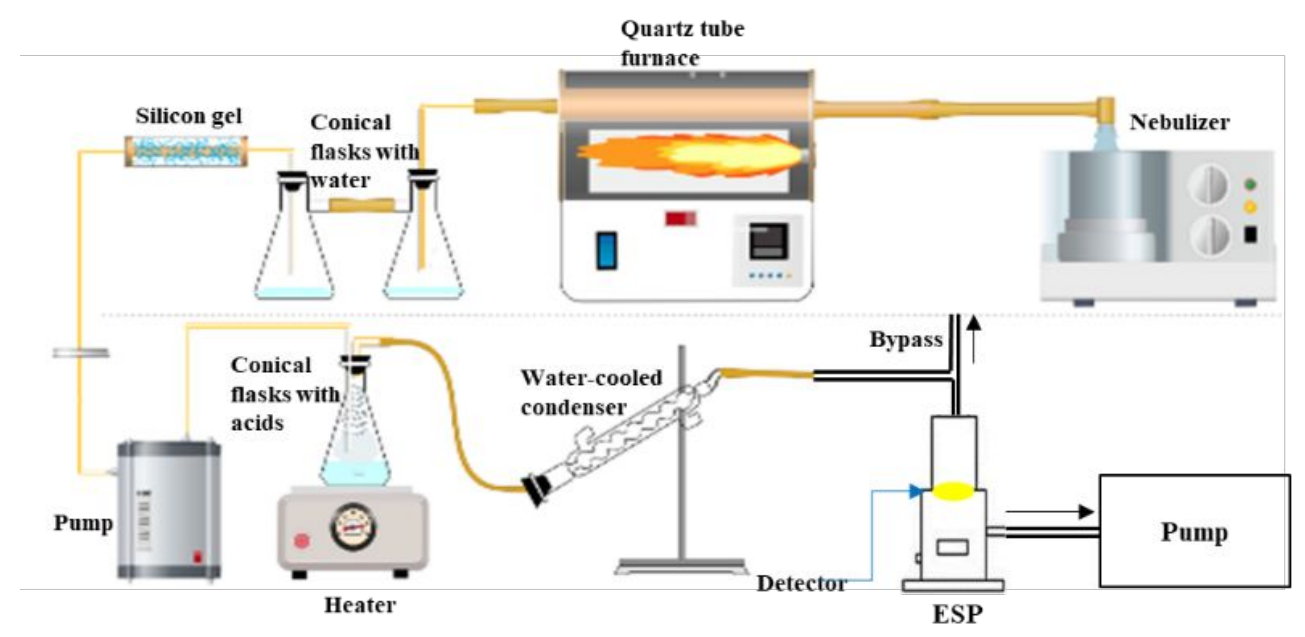

Figure S2 Generation and collection system of standard acidic particles

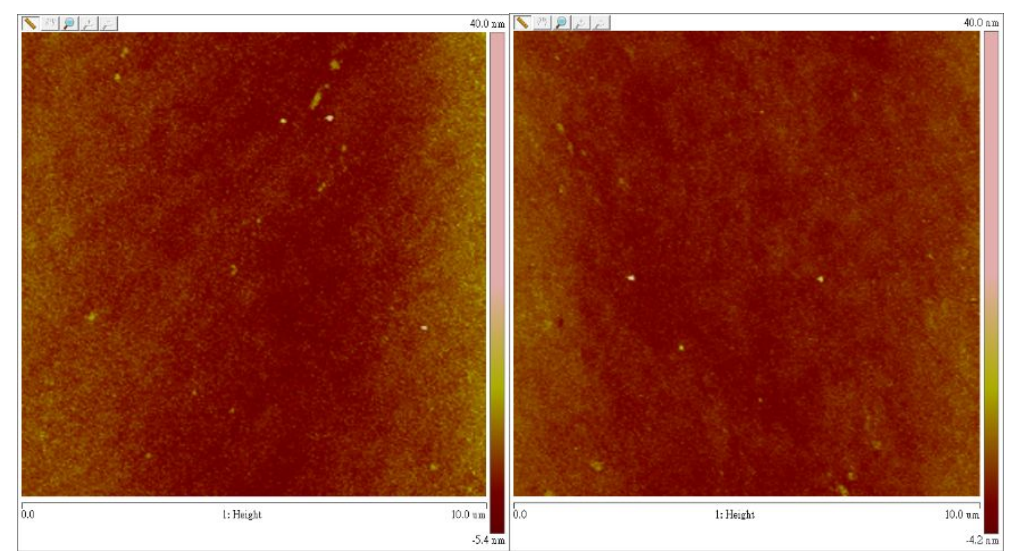

Figure S3 AFM images of non-acidic particles after ultrasonic treatment with ethanol for $10 \mathrm{~min}$ (left) and $20 \mathrm{~min}$ (right)

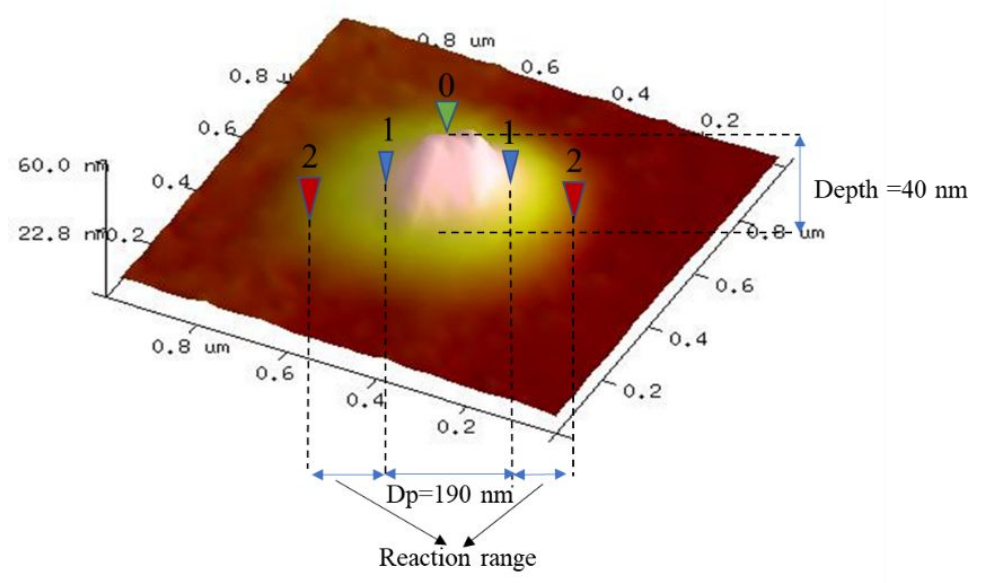

Figure S4 AFM zoomed 3D-image of an acidic particle on the surface coated with a nano-film metal before the ultrasonic treatment 


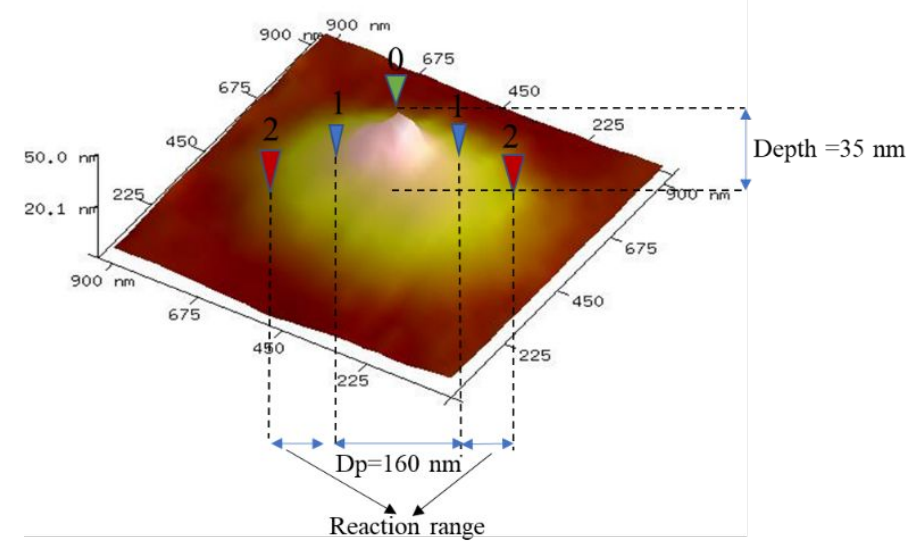

Figure S5 AFM zoomed 3D-image of an acidic particle on the surface coated with a nano-film metal after the ultrasonic treatment 